\title{
BLOCKADE OF THE BIOCHEMICAL CORRELATES OF CONTRACTION AND RELAXATION IN UTERINE AND INTESTINAL SMOOTH MUSCLE*
}

\author{
Theodore M. Brody† and Jack Diamond \\ Department of Pharmacology, \\ University of Michigan Medical School, \\ Ann Arbor, Mich.
}

The relationship between contraction and glycogen phosphorylase activation by adrenergic agents has been studied extensively in cardiac and skeletal muscle (see review by Haugaard \& Hess, 1965). It was suggested by Bülbring in 1960 that smooth muscle relaxation induced by epinephrine was a process requiring increased metabolic energy; and early results (Axelsson et al., 1961) indicated that the action of epinephrine on the smooth muscle cell membrane might be related to its ability to increase phosphorylase $a$ activity. However, later reports concluded that the two effects were not related (Timms et al., 1962 ) and that, in fact, the increases in phosphorylase $a$ activity seen in previous experiments were artifactual (Bueding et al., 1962).

The present study is concerned with the effects of catecholamines and adrenergic blocking agents on the motility and phosphorylase activity of isolated rat uterus and guinea pig taenia coli.

\section{Nature of the Adrenergic Receptors in the Rat Uterus}

In a previous study (Diamond \& Brody, 1966a), the effects of several catecholamines and adrenergic blocking agents on the motility of the isolated estrogen-primed rat uterus were investigated. All three catecholamines studied (epinephrine, norepinephrine, and isoproterenol) completely inhibited spontaneous uterine contractions. This inhibitory action was prevented by pretreatment of the uteri with beta adrenergic blocking agents but not by alpha blocking agents. The presence of alpha adrenergic excitatory receptors was also demonstrated by the observations that (1) in the presence of the beta adrenergic blocking drug, propranolol, both epinephrine and norepinephrine stimulated uterine motility and (2) this stimulatory action was abolished by the alpha adrenergic blocking agents, phenoxybenzamine and phentolamine. Furthermore, isoproterenol produced no stimulation in the presence of propranolol. Thus, the isolated estrogen-primed rat uterus appeared to contain primarily beta inhibitory receptors, but the presence of alpha excitatory receptors could also be demonstrated.

*Supported in part by a contract between The University of Michigan and The Office of Naval Research (NONR 1224-27) and by The University of Michigan Cancer Research Institute.

$\dagger$ Present address: Department of Pharmacology, Michigan State University, East Lansing, Mich.

$\ddagger$ Present address: Division of Medical Science, Brown University, Providence, R. I. 


\section{Relationship Between Catecholamine-Induced Relaxation and Phosphorylase Activation in Uterine Smooth Muscle}

In other experiments described in the above paper, it was shown that all three catecholamines were capable of increasing phosphorylase $a$ activity in the isolated rat uterus. As with uterine relaxation, uterine phosphorylase activation induced by catecholamines was prevented by beta blocking agents but not by alpha blocking drugs. The two effects (i.e., phosphorylase activation and inhibition of spontaneous motility) could not be dissociated by using very small doses of epinephrine. The smallest dose of epinephrine which consistently relaxed the uterus $\left(6 \times 10^{-9} \mathrm{M}\right)$ also significantly increased phosphorylase $a$ activity. However, a nonadrenergic smooth muscle relaxant, nitroglycerin, completely inhibited spontaneous uterine contractions but had no effect on uterine phosphorylase activity. Thus, it appeared that phosphorylase activation was not related to uterine relaxation per se but was a specific effect of the catecholamines. Whether the catecholamine-induced relaxation and phosphorylase activation were causally related phenomena could not be decided from these experiments. They are, however, related to the extent that both appear to be beta adrenergic effects.

\section{Nature of the Adrenergic Receptors in Guinea Pig Taenia Coli}

The effects of several catecholamines and adrenergic blocking agents on the motility of isolated guinea pigs taenia coli are shown in FIGURE 1. All three catecholamines completely inhibited spontaneous contractions in this tissue. However, in contrast to the receptor pattern previously observed in the rat uterus, the guinea pig taenia coli appeared to possess both alpha and beta inhibitory receptors. This is indicated by the observation that the relaxation induced by epinephrine is not prevented by pretreatment with either propranolol or phentolamine alone, but is completely blocked by pretreatment with a combination of smaller concentrations of the two adrenergic antagonists (see middle panel in FIGURE 1). Similarly, both propranolol and phentolamine were required to block the relaxant effect of norepinephrine, whereas propranolol alone was capable of preventing the relaxation caused by isoproterenol. These results are in agreement with the earlier reports of Ahlquist \& Levy (1959) and Furchgott (1960) on the canine and rabbit ileum.

\section{Relationship Between Catecholamine-Induced Relaxation and Phosphorylase Activation in Taenia Coli}

The effect of epinephrine on phosphorylase activity of isolated guinea pig taenia coli was studied in the light of the adrenergic receptor pattern observed in that tissue in the previous experiments. Epinephrine, in a concentration of $6 \times 10^{-7} \mathrm{M}$ or $3 \times 10^{-6} \mathrm{M}$, was shown to increase phosphorylase $a$ activity in the taenia coli. FIGURE 2 illustrates the effect of $3 \times 10^{-6} \mathrm{M}$ epinephrine on phosphorylase activity of taenia coli at various times after addition of the drug 
to the muscle bath. It can be seen that phosphorylase a activity was not increased at 15 seconds after addition of epinephrine, even though the muscle was ordinarily relaxed within 10 seconds. Thus, it is apparent that catecholawas ordinarily relaxed within 10 seconds. Thus it is apparent that catecholamine-induced relaxation can occur without phosphorylase activation. FIGURE 2 also shows that phosphorylase $a$ activity is definitely elevated in taenia coli at 30 seconds and 2 minutes after the addition of epinephrine. In contrast to the conclusions of Bueding et al. (1962), this rise in phosphorylase $a$ does not appear to be artifactual.

The effects of adrenergic blocking agents on this epinephrine-induced phosphorylase activation are shown in FIGURE 3 . The concentrations of drugs used in these experiments were the same as those used in the middle tracing of FIGURE 1. Samples were removed for phosphorylase assay two minutes after addition of epinephrine. It is apparent that propranolol alone, in a concentration which did not block the relaxing effect of epinephrine, did block the rise in phosphorylase $a$ usually seen after the catecholamine. Phentolamine alone blocked neither the relaxing effect nor the increase in phosphorylase $a$ activity. Both propranolol and phentolamine together did not produce any greater blockade of the phosphorylase $a$ response than did propranolol alone, even though the combination blocked relaxation whereas propranolol alone did not. These results demonstrate the existence of an alpha adrenergic component of
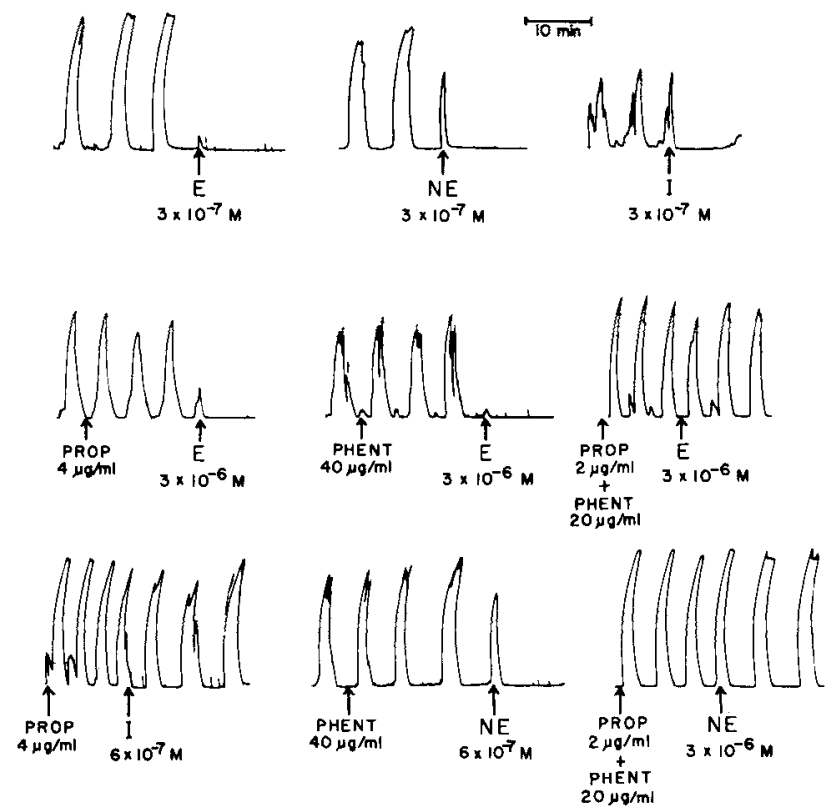

FIGURE 1. Effect of catecholamines and adrenergic blocking agents on the motility of isolated guinea pig taenia coli. Abbreviations are as follows: $\mathrm{E}$, epinephrine; $\mathrm{NE}$, norepinephrine; I, isproterenol; PROP, propranolol; PHENT, phentolamine. 


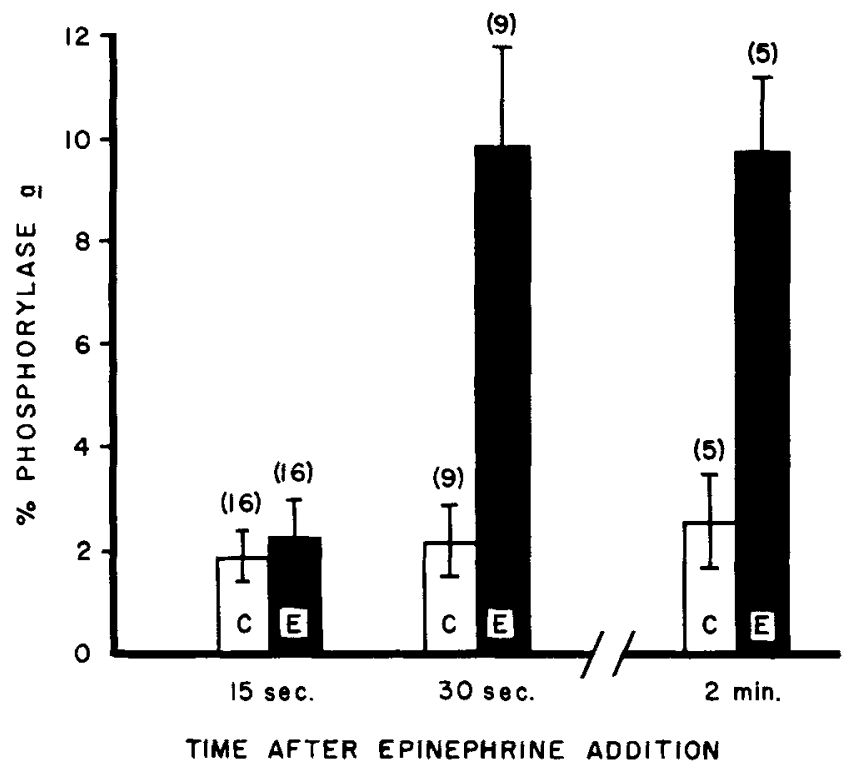

FIGURE 2. Effect of epinephrine $\left(3 \times 10^{-6} \mathrm{M}\right)$ on phosphorylase activity of isolated guinea pig taenia coli. Bar graphs represent mean values - standard errors. Numbers in parentheses refer to the number of animals in each experiment. $C$ represents controls and $\mathrm{E}$ represents epinephrine-treated preparations.

relaxation in taenia coli, which is not associated with an increase in phosphorylase activity.

TABLE 1 shows the time of onset of relaxation after the addition of epinephrine and isoproterenol to isolated taenia coli. Epinephrine in a concentration of $3 \times 10^{-6} \mathrm{M}$ and $6 \times 10^{-7} \mathrm{M}$ caused the muscles to relax within 11 seconds and 14 seconds respectively. However, an equimolar dose of isoproterenol $\left(6 \times 10^{-7} \mathrm{M}\right)$ did not produce relaxation until 28 seconds after addition. Furthermore, when the large dose of epinephrine was added in the presence of the alpha blocking agent phentoamine, the time of onset of relaxation was increased to 25 seconds. Thus, the alpha adrenergic component of relaxation, which is not associated with an increase in phosphorylase $a$ activity, appears to occur earlier in time than the beta adrenergic component, which is accompanied by a rise in phosphorylase $a$. This is in agreement with the data presented in FIGURE 2 where epinephrine caused a relaxation of the taenia coli within 15 seconds without increasing phosphorylase a activity. This early relaxation appears to be due to the phosphorylase-independent, alpha adrenergic component of epinephrine's action. However, at 30 seconds or 2 minutes after addition of the drug, when the beta adrenergic component of epinephrine-induced relaxation is manifest, phosphorylase $a$ activity is indeed increased. These observations may explain the dissociation between phosphorylase activation and relaxation seen by Bueding et al. (1962), since these 


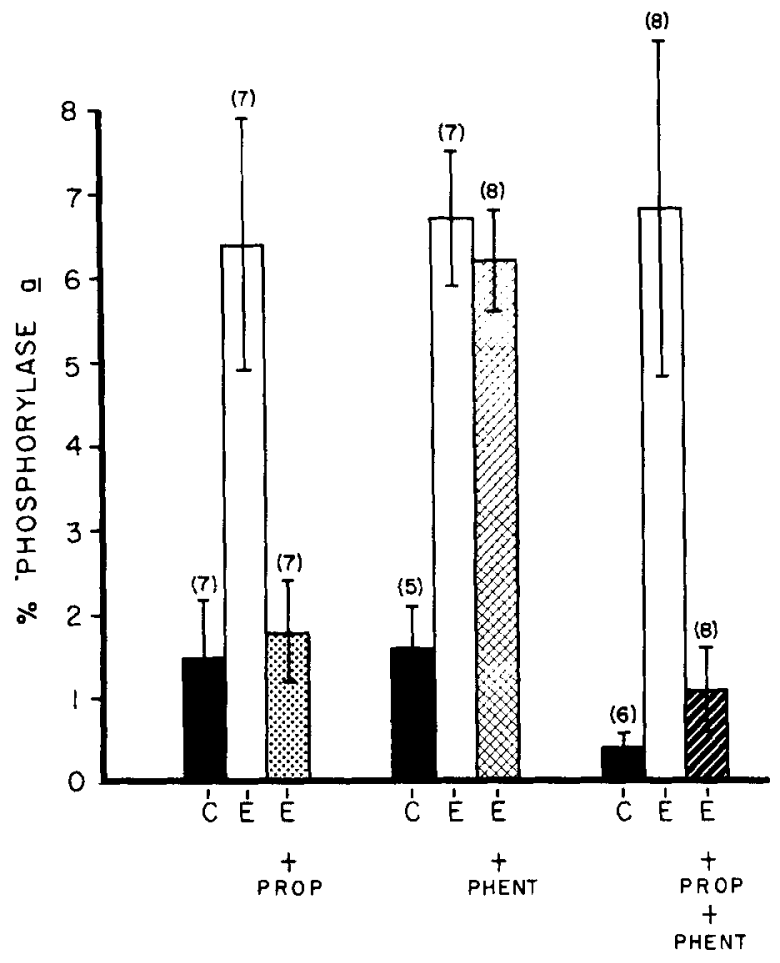

FIGURE 3. Effect of adrenergic blocking agents on epinephrine-induced phosphorylase activation in isolated guinea pig taenia coli. C represents controls and $E$ represents $3 \times 10^{-6} \mathrm{M}$ epinephrine. Concentrations of propranolol (PROP) and phentolamine (PHENT) were the same as those shown in FIGURE 1. In all experiments, samples were removed for phosphorylase assay two minutes after addition of epinephrine.

TABLE 1

ONSET OF RELAXATION AFTER ADDITION OF EPINEPHRINE AND ISOPROTERENOL TO ISOLATED TAENIA COLI

\begin{tabular}{l|r|c}
\hline \multicolumn{1}{c|}{ Treatment } & $\mathrm{N}$ & $\begin{array}{c}\text { Onset of Relaxation } \\
\text { (seconds) }\end{array}$ \\
\hline Epinephrine $\left(3 \times 10^{-6} \mathrm{M}\right)$ & 12 & $11.0 \pm 1.4$ \\
Epinephrine $\left(6 \times 10^{-7} \mathrm{M}\right)$ & 5 & $13.8 \pm 2.9$ \\
Isoproterenol $\left(6 \times 10^{-7} \mathrm{M}\right)$ & 8 & $28.4 \pm 3.1$ \\
Epinephrine $\left(3 \times 10^{-6} \mathrm{M}\right)$ after \\
Phentolamine $\left(1 \times 10^{-4} \mathrm{M}\right)$
\end{tabular}


authors measured phosphorylase activity at very early times (5-15 seconds) after the addition of epinephrine.

In subsequent reports, Bueding \& Bulbring (1964) and Bueding et al. (1966) have suggested that the relaxing action of epinephrine on guinea pig taenia coli may be directly related to increases in the tissue concentration of cyclic $3^{\prime}, 5^{\prime}$-AMP. This hypothesis is based on the observation that increases in the concentration of the cyclic nucleotide are observed at times after epinephrine administration which correlate well with the onset of relaxation (7-15 seconds). However, our data suggest that the early component of epinephrine-induced relaxation in taenia coli is alpha adrenergic in nature and can occur in the presence of a beta blocking agent. In all other tissues in which it has been studied, stimulation of cyclic $3^{\prime}, 5^{\prime}$-AMP production has been associated with beta adrenergic phenomena. Therefore, pretreatment of taenia coli with beta adrenergic blocking agents should prevent the epinephrineinduced increases in cyclic $3^{\prime}, 5^{\prime}$-AMP without affecting the relaxation produced by the catecholamine. Such experiments will have to be done before any conclusions can be reached about the correlation between increases in cyclic $3^{\prime}, 5^{\prime}-\mathrm{AMP}$ and relaxation in taenia coli.

\section{Possible Sites of Action of Epinephrine on Intestinal Smooth Muscle}

The above data indicate that epinephrine can inhibit the motility of isolated taenia coli via actions at two distinct sites or receptors; one alpha adrenergic in character and the other beta adrenergic. FIGURE 4 illustrates a hypothetical scheme for the location of these adrenergic sites in intestinal smooth muscle, based on our results and those of others. We believe that the beta site is within the muscle cell itself, since its activation is slower in onset and is accompanied by a metabolic response within the cell. Three possibilities have been suggested for the alpha site in intestinal smooth muscle.

1. The first possibility is that the catecholamine may be acting at the ganglion cells in the myenteric plexus supplying the muscle. Histological evidence for such a possibility has been provided by Norberg (1964) and Jacobowitz (1965), and pharmacological evidence indicates that epinephrine is capable of preventing transmission in some types of autonomic ganglia (McIsaac, 1966).

2. A second possibility is suggested by the experiments of Kosterlitz \& Watt (1965) who concluded that the alpha receptors in guinea pig ileum are situated in the neurones innervating the longitudinal muscle, and the beta receptors are in the muscle itself.

3. Another possible location for the alpha site is at the muscle cell membrane itself where epinephrine might act by affecting the permeability or electrical activity of the cell membrane. Preliminary experiments in our laboratory indicate that, in taenia coli, the first two sites are less likely than 


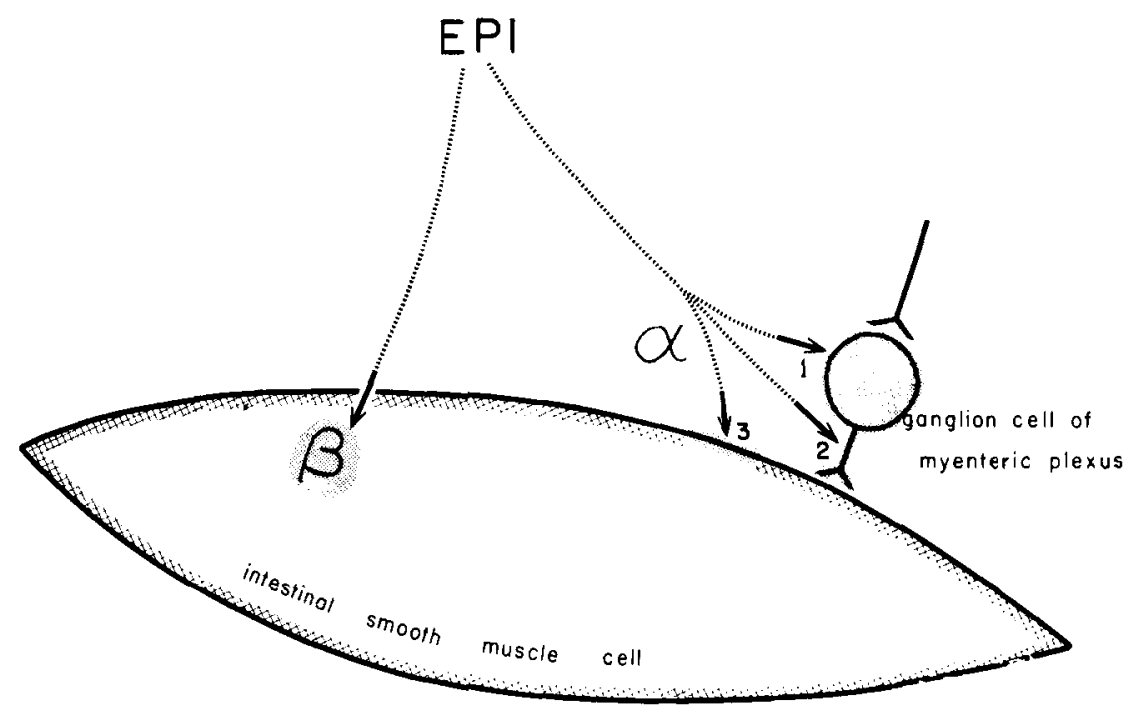

FIGURE 4. Hypothetical scheme showing possible locations for the alpha and beta adrenergic receptor sites in intestinal smooth muscle. See text for explanation.

the third. For example, an alpha r crenergic component of relaxation can still be demonstrated in preparations that have been treated with high concentrations of ganglionic blocking agents and/or cocaine. Therefore, we believe that the most likely alpha site in taenia coli is at the muscle cell membrane. This is in agreement with the data and conclusions presented by Jenkinson \& Morton (this monograph).

\section{Relationship Between Contraction and Phosphorylase Activation in Smooth Muscle}

The possibility of a relationship between smooth muscle contraction and phosphorylase activation has also been investigated using isolated rat uteri and guinea pig taenia coli. The results of these studies have been presented in a previous publication (Diamond \& Brody, 1966b). All of the agents which stimulated uterine motility in these experiments were also found to increase uterine phosphorylase $a$ activity. These included serotonin, acetylcholine, bradykinin, oxytocin, and barium chloride. Furthermore, studies with pharmacological blocking agents indicated that whenever the drug-induced stimulation of motility was prevented, the phosphorylase activation was also blocked. Therefore, it appeared that the two phenomena were related. Temporal studies, in which uterine phosphorylase activity was measured at early time intervals after the start of serotonin-induced contractions, indicated that the contraction preceded the phosphorylase activation by at least $4-5$ seconds. 
Further experiments reported in the above paper showed that phosphorylase $a$ activity also increased during spontaneous contractions (no drug added) in isolated uteri and taenia coli. As was the case with the drug-induced contractions, the spontaneous contractions appeared to precede the phosphorylase activation. Reserpine pretreatment or beta blocking agents had no effect on these spontaneous contractions or the phosphorylase changes accompanying them. The above results led to the conclusion that smooth muscle contraction and phosphorylase activation are related, and that the enzyme activation may be a result of the muscle contraction since it follows it in time. Possible mechanisms of phosphorylase activation induced by the contractile event have been considered elsewhere (Diamond \& Brody, 1966b).

\section{Summary and Conclusions}

In the isolated rat uterus, both relaxation and phosphorylase activation appear to be beta adrenergic effects, but whether they are causally related or independent phenomena cannot be decided from the available data.

In the isolated guinea pig taenia coli, relaxation can be accomplished by stimulation of either alpha or beta adrenergic receptors. The alpha adrenergic component of relaxation is more rapid in onset and is not associated with an increase in phosphorylase activity. This alpha effect does not seem to be associated with a metabolic effect but may be responsible for changes in the electrical activity of the cell membrane. The beta adrenergic component is slower

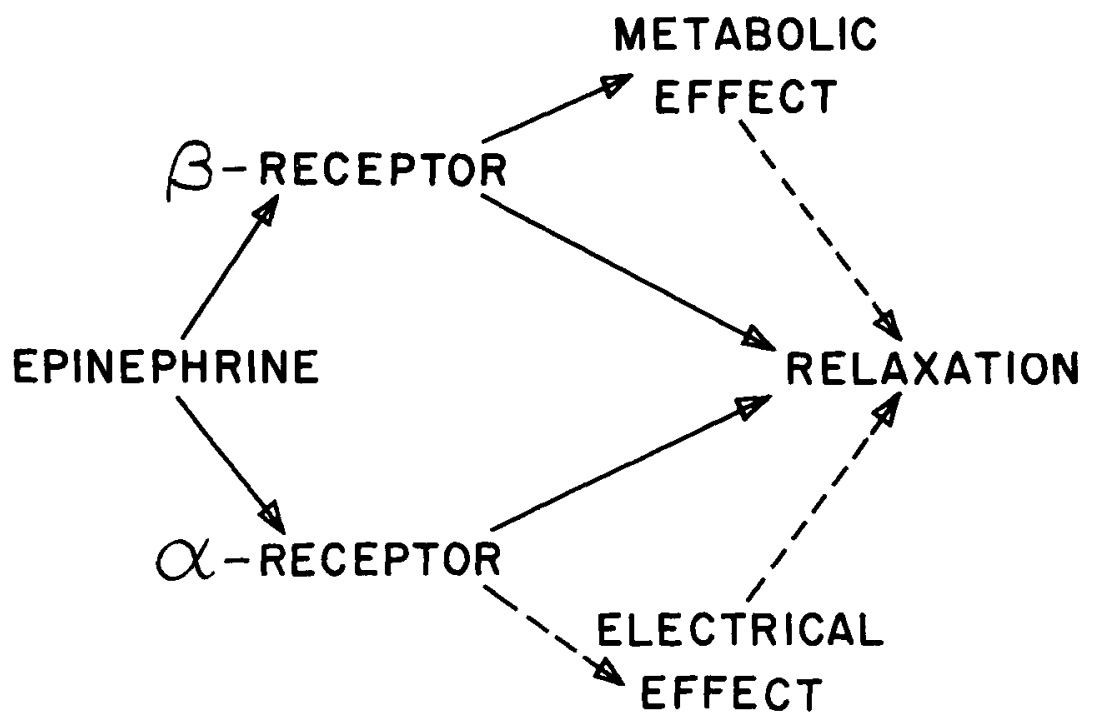

FIGURE 5. Possible relationships between the physiological and metabolic effects of epinephrine in guinea pig taenia coli. Solid lines represent clearly established relationships; broken lines represent relationships which have not been definitely established. 
in onset and is accompanied by an increase in phosphorylase a activity. However, as was the case for uterine smooth muscle, a causal relationship between the beta relaxation and the phosphorylase activation has not been established. The above relationships have been diagrammed in FIGURE 5 . It should be noted that the metabolic effect and the physiological event (shown in FIGURE 5 ) could conceivably result from an increase in the formation of cyclic $3^{\prime}, 5^{\prime}$ AMP. However, we have not measured this compound. There appears to be some relationship between contractile activity in intestinal smooth muscle and phosphorylase activation. Our data suggest that the enzyme activation occurs as a result of the muscle contraction since it follows it in time.

\section{References}

AHLQUIST, R. P. \& B. LEVY. 1959. Adrenergic receptive mechanism of canine ileum. J. Pharmacol. 127: 146-149.

AXELSSON, J., E. BUEDING \& E. BULBRING. 1961. The inhibitory action of adrenaline on intestinal smooth muscle in relation to its action on phosphorylase activity. J. Physiol. 156: 357-374.

BUEDING, E. \& E. BULBRING. 1964. The inhibitory action of adrenaline. Biochemical and biophysical observations. Proc. Sec. Int. Pharmacol. Meeting 6: 37-56.

BUEDING, E., E. BÚLBRING, H. KURIYAMA \& G. GERCKEN. 1962. Lack of activation of phosphorylase by adrenaline during its physiological effect on intestinal smooth muscle. Nature (Lond.) 196: 944-946.

BUEDING, E., R. W. BUTCHER, J. HAWKINS, A. R. TIMMS \& E. W. SUTHERLAND, JR. 1966. The effect of epinephrine on cyclic adenosine $3^{\prime}, 5^{\prime}$-phosphate and hexose phosphates in intestinal smooth muscle. Biochim. Biophys. Acta 115: 173-178.

BULBRING, E. 1960. Biophysical changes produced by adrenaline and noradrenaline. In Ciba Foundation Symposium, Adrenergic Mechanisms. : 275-287. Churchill, London.

DIAMOND, J. \& T. M. BRODY. Effect of catecholamines on smooth muscle motility and phosphorylase activity. J. Pharmacol. (In press.)

DIAMOND, J. \& T, M. BRODY. Relationship between smooth muscle contraction and phosphorylase activation. J. Pharmacol. (In press.)

FURCHGOT'T, R. F. 1960. Receptors for sympathomimetic amines. In Ciba Foundation Symposium, Adrenergic Mechanisms. : 246-252, Churchill, London.

HAUGAARD, N. \& M. E. HESS. 1965. Actions of autonomic drugs on phosphorylase activity and function. Pharmacol. Rev. 17: 27-69.

JACOBOWITZ, D. 1965. Histochemical studies of the autonomic innervation of the gut. J. Pharmacol. 149: 358-364.

JENKINSON, D. H. \& I. K. M. MORTON. 1966. Adrenergic blocking drugs as tools in the study of the actions of catecholamines on the smooth muscle membrane. This Annal.

KOSTERLITZ, H. W. \& A. J. WATT. 1965. Adrenergic receptors in the guinea pig ileum. J. Physiol. 177: 11.

MCISAAC, R. J. 1966. Ganglionic blocking properties of epinephrine and related amines. Int. J. Neuropharmacol. 5: 15-26.

NORBERG, K. A. 1964. Adrenergic innervation of the intestinal wall studied by fluorescence microscopy. Int. J. Neuropharmacol. 3: 379-382.

TIMMS, A. R., E. BUEDING, J. T. HAWKINS \& J. FISHER. 1962. The effect of adrenaline on phosphorylase activity, glycogen content, and isotonic tension of intestinal smooth muscle (taenia coli) of the guinea pig. Biochem. J. 84: 80 . 